\title{
A Study on Several Issues in Chinese Modern Music History
}

\author{
Yong Lu
}

\author{
College of Music, Hubei Engineering University, Xiaogan, 432000, China
}

\author{
Keywords: Modern music history, Research category, Rewriting, Teaching
}

\begin{abstract}
According to the research status of recent years, this paper discusses several issues which the academic field pays attention to, such as the research status of Chinese modern music history and music history, the research category of the Chinese modern music history, the rewriting issue of the Chinese modern music history, the education issue of the Chinese modern music history, and put forward my own opinions. These opinions will help the study of the Chinese modern music history.
\end{abstract}

\section{Introduction}

The so called music history is the course of history in which music happened and developed. The reason why the Chinese modern music history study can continually get developed and expanded is the result of all these efforts made by research field. Without the extremely bitter and hard efforts made by the scholars in the music history, there will be no prosperous situation of the music history study today. Then the author of the paper will focus on several issues on the Chinese modern music history and discuss them.

\section{The discussion on the research category of the Chinese modern music history}

The discussion on the research category of the Chinese modern music history began in the 1980s.Liu Jingzhi, Dai Penghai, Feng Wenci, Chen lingqun and other experts in the field of Chinese modern music history published their academic papers to express their own opinions upon this issue. In 1963, scholar Chen Lingqun published papers on several issues of Chinese modern music history and made reasonable analysis. The opinions involved in the paper are still new in today's view. And she made great influence on the study of Chinese modern music history. Chen pointed out that the composing of the Chinese modern music history papers has to follow the three requirements as below: 1. The compilations should include all nations' music development histories not only Han nation's. 2. The compilations should not only include newly developing music history, but also include the traditional music history of China which includes folk song, song and dance, traditional opera, instrumental music, religious music And Their evolve status, then make an overall review. 3. The compilations should not only include partial composers' individuality and their creations, but also include the people's music life and their activities, the evolution of national folk music category with traditional significance, major activities of professional and non professional composers and music performers or groups, music creation, music theory, music education and all music phenomena. The requirements above have covered the whole status of music culture. The three requirements above are the important criterions of the books on Chinese modern music history.

As to the subject of the Chinese modern music history, the study subject is the new music and the professional music which affected by music in developed countries or the Chinese national folk music with traditional significance? The obscure and contradictory of the study subject in Chinese modern music history demonstrate the problems in the Chinese modern music history.

In the process of academic study, we shouldn't use the music history of Han nationality to replace the music history of other minorities and we shouldn't use new music to replace traditional music. The both sides should be reasonably balanced. The compilations of Chinese modern music history not only need the contribution from professional music creators but also need the positive functions of the music culture from the people; not only to study the developing process of modern new music, but also demonstrate the evolution history of modern folk music of different nationalities. When it comes to the requirement for the composition of Chinese modern music history, Chen Lingqun put forward 
four points of opinions: The first is that the history records have to study the developing process of Chinese modern music with an overall point of view, but we cannot demand it to contain all the music phenomena. History book that really covers all the things on earth doesn't exist and has no necessity to exist. The second is to clarify and distinguish the purpose and features of general music history study and specific music history study respectively. The third is that we need a process of preparation and accumulation of long term to compose the overall modern general music history. It cannot be accomplished in a short time. The fourth is that we need to accumulate more different documentaries about modern music history. This is because only depend on small part of study documentaries or small part of scholars we cannot get a modern general music history with completed content, accurate data and rigorous textual study. We need the related side to provide us with close and deeper cooperation.

Mr. Chen made a highly refined summarization on the study category of Chinese modern music history. He linked the developing characteristics of Chinese modern music history with that of Chinese modern history. From the view of macro-history, the Chinese modern music history is a history in which under the drastic social changes and the western music culture influences the national music culture made its transformation to modernization. The Chinese modern music history made many changes to Chinese traditional music from which complicated types of national music got prosperously developed, and formed a new music culture which was influenced by western music culture more directly and had difference with traditional music but also had profound connection. The continuously changing traditional music and the new type music under the innovative development together formed the subject of Chinese modern music history. Therefore, the study category of Chinese modern music history should include traditional music and new type music. Both of them are under continuous changing and development from which the animate contents of Chinese modern music history were born.

\section{The discussion on the rewriting issue of The Chinese modern music history}

In recent years, the topic of rewiring Chinese modern music history is heating up. Especially in the beginning of the century, this issue of common sense caused a large scaled discussion in Chinese music history research community. The discussion directly concerns with the reconstruction of Chinese modern music history and the general layout and further development. So this discussion deserves us to make deeper study. Rewriting is an important academic controversy involving with the course system construction of Chinese modern music history. The participants are famous scholars and people with personal historical experience such as Wang yuhe, Dai Penghai, Zhang Jingwei, Ju Qihong. To conclude, the rewriting issue of Chinese modern music history mainly demonstrates the following features.

The first is to form the new consensus by preinstall conceive to realize the goal of rewriting. In the heated discussion, many scholars are trying to create a rewriting system of Chinese modern music history with macro conceive. For example, Feng Wenci suggested that the new history should be formed by the connection between the ancient and the modern and the together development of two different traditions. So, new wisdom can be contributed to the discussion of rewriting. We can say the goal which preset the history writing demonstrates the noble sense of responsibility and mission of the scholars. However how can we make sure the range if it is carried out? It is difficult to predict. Therefore, on the foundation of reasonable identification some of the scholars suggest innovation. Wang Yuhe advocates the suggestion that two traditions coexist and the modern connects with the past. It is necessary to chase after the ideal goal, but in the practical situation it is very difficult to be put into practice. Ju Qihong thinks this idea is a very nice one, and he also puts forward that due to the enormous scale, it doesn't have practical operability to expand the modern music history. Therefore, the discussion on the rewriting of Chinese modern music history is the goal of the subject construction and also the precious academic research resource for the scholars. But in the practical operation we should continuously enhance the construction of Chinese modern music history and grab the research opportunities, use innovation as precondition, prepare for the groundwork. 
The second is to use tolerant and harmonious view to discuss the study of Chinese modern music history. The main objective of rewriting issue of Chinese modern music history is analyzed from the history and the current situation of Chinese modern music. Some scholars think that we should insist the diversified trend under the tolerant research environment. The opinion of Dai Jiafang is that we should be more tolerant. The categories of Chinese modern music history should be various. In the rewriting background, there's problem in reconstruct the music history in the angle of theories. But when it comes to the practical operation, we should not be controlled by ideology. He Muhuan put forward that rewriting is based on avoiding the main stream ideology which easily leads the music history writing to blindness or misreading. Guided by the western conceptions, the phenomenon that judge the status in the music history from the confront status of the main stream ideology is in fact a kind of political judgement. This scholar put forward this opinion after observing the current rewriting of the music history. I think the objective contradiction does exist in the modern music history. So in the discussion of rewriting modern music history, we should be more objective to the history and use a tolerant view to treat the study of modern music history.

The third is to carry out Chinese modern music history study with foresight. Chen put forward that once we hope to require achievement in the discussion of the rewriting of Chinese modern music history, we must use constructive thoughts and abandon criticism thoughts. Only criticize not to construct is not acceptable, while if criticize too much will make people flinch. We should pay attention to effectiveness and sureness. Nowadays, the study of Chinese modern music history in the tide of marketing economy is already at the edge. So, we should waste precious research resources on the issues we can hardly get consensus. We should do more realistic works through communication to promote the sustainable development of this science.

\section{The discussion on the teaching issue of Chinese modern music history}

For all the time, the Chinese modern music history is the precious and abundant educational resource. But why most of the students cannot be interested in it during the class? The main reason is that history is talked about in the view of history itself, rather than taking the history as a mirror, not to mention that use the history to promote the development of music career. As we know, after the dynamic the May 4th Movement, CPC was established. Mr. Sun Yat-sen reformed the KMT and carried out the revolution associated with CPC. Then the Huangpu Military Academy was established based on which the Northern Expeditions could be carried out. Industrial workers from place to place carried out anti-imperialism and anti-feudalism struggles under the correct leadership of CPC. During this time some songs were formed which had the irreplaceable function in uniting the people in the revolution. But in 1927, Chiang Kai-shek betrayed the revolution, and lunched the 412 counterrevolutionary coup. Many Communists got bloodshed, but Communists had never been frightened by the reactionist. They began new battles. The Nanchang uprising broke out in 1927 was the sign of the birth of the communism independent military force. Thus the new way of fighting against the slaughter of KMT Reactionaries was born. Then the songs of Red Army were spread to the whole land of China. And the anti Japanese war broke out the Communist literary and art workers and the people in enemy's rear area not only picked up fighting weapons but also art weapons. They used the songs as the weapons to accuse the atrocity of the Japanese army and to promote the morale of our side. During the war of liberation, the art propaganda in the front line played an important role in the mobilization. Making modern college students to know the developing history of modern music can make them give up the stereotypes on modern music history and draw their interest to study. To do so, we need to achieve the following three points: First is to introduce the magnificent music history of modern China. For example, students could discuss the relationship between the songs such as When to wake, Song of the motherland and the national salvation thoughts after the failure of Sino- Japanese war, or the influence of the western music thought on Chinese traditional music. Music expresses the voice of people through the form of score. The music history is a mirror of the development of a nation. The second point is that the music education without the sense of history in higher institutes is a kind of blind and ignorant training. Since When to wake, to The song of the young pioneers, Hope for the red army, then to March of the army of volunteers, Yellow river Cantata, the theme of the 
music emphasizes patriotism. The developing history of Chinese modern music history is the demonstration for the patriotic theme of the nation. The third is that the teaching of modern music history must motivate more teaching methods. On the foundation of emotion, convince people with reasoning. Different phenomena in Chinese modern music history are the results of blood and fire. Therefore, multimedia method can be applied in the music history teaching in higher institutes. Compose different teaching softwares with different modules thus the students can be led into the exciting world of modern music history.

\section{Conclusion}

In conclusion, the Chinese modern music history not only promotes professional music studies, but also strongly improves the morality education in colleges. The analyses above are shallow discoveries. We still need systematic and scientific researches on the music education system to develop the Chinese modern music history study better.

\section{References}

[1] Chen Lingqun. The Chinese modern music history in 20th century. Shanghai : Shanghai Conservatory of Music Press,2004.

[2] Chang Xiaojing. The social history coordinate of music history-on the way of writing of the Chinese modern music history. Journal of Huaqiao University(philosophy and social science),2006(1).

[3] Yang Heping. The Chinese modern music history study since the reform and opening up policy. People’s music,2009(7).

[4] Dai Jiafang,Zhang Juan. The review and expectations of the development of the Chinese modern music history in the new age . Journal of Central Conservatory of Music,2010(1).

[5] Li Shuqin. From political to academic-a review on the scientific construction of the Chinese modern music history. Journal of Central Conservatory of Music, 2012(4). 